\title{
Epidemiology of Avian Ectoparasitic Infestations Diagnosed in Osun State Veterinary Hospitals, Southwest Nigeria
}

\section{Shola D. OLA-FADUNSIN ${ }^{1 *}$, Fufa I. GIMBA², Donea A. ABDULLAH ${ }^{3}$, Mohammed KONTO ${ }^{4}$}

\author{
${ }^{1}$ University of Ilorin, Faculty of Veterinary Medicine, Department of Veterinary Parasitology and Entomology, P.M.B. 1515, Ilorin, Kwara \\ State,Nigeria; olashodam2@yahoo.com (*correspondingauthor) \\ ${ }^{2}$ Taraba State Ministry of Agriculture and Natural Resources, Avian Influenza Control Project Animal Health Component Desk Office, Jalingo, \\ Taraba State, Nigeria \\ ${ }^{3}$ Northern Technical University, Department of Animal Production, Mosul, Iraq \\ ${ }^{4}$ University of Maiduguri, Faculty of Veterinary Medicine, Department of Veterinary Parasitology and Entomology, Maiduguri, \\ Borno State, Nigeria
}

\begin{abstract}
Ectoparasitism is the most devastating parasitic condition of poultry after coccidiosis. This study was conducted to identify the risk factors associated with avian ectoparasitism in Osun State, Nigeria. Data was obtained from avian species presented at the major Veterinary Hospitals in Osun State between January 2006 and December 2015. A total of 4,584 avian species were presented in the period under review. Of the presented birds, 2,665 (58.14\%) were young while 1,919 (41.86\%) were adults. One thousand nine hundred and ninety four $(43.50 \%)$ were male and 2,590 (56.50\%) were female. More birds $(2,868$, $62.57 \%)$ were presented during the wet season compared to the dry season $(1,716,37.43 \%)$. Turkeys $2,088(45.55 \%)$ were the most frequently presented bird type followed by layers 1,476 (32.20\%) and local chickens 1,020 (22.25\%). A total of 324 (7.07\%) avian species was diagnosed for ectoparasitic infestations of which lice infestation was the most prevalent $(216,4.71 \%)$ followed by flea infestation $(72,1.57 \%)$, tick infestation $(24,0.52 \%)$ and mite infestation $(12,0.26 \%)$. There was no defined pattern in the yearly and monthly prevalence of ectoparasite infestations. Age, sex, seasons and species were significantly associated $(P<0.05)$ with the prevalence of ectoparasitic infestations. This study showed a low prevalence of ectoparasite infestations among avian species in the study area; however strategic measures should be taken to control these ectoparasites in Osun State, Nigeria, so as to maximize productivity in the poultry sector.
\end{abstract}

Keywords: age; ectoparasite infestations; season; sex; species

\section{Introduction}

Avian species such as poultry (indigenous chickens, broilers, layers, cockerels), turkeys, ducks, guinea fowl, peasants, pigeons and ostriches are some of the most reared animals in many parts of the world because of their productivity and other purposes which include ornamentations (Mohammed and Sunday, 2015; Malann et al., 2016). In Nigeria, poultry industry plays an important role in the provision of animal protein (meat and egg) to man and it occupies a vital position in the national economy as a source of revenue. Poultry production is one of the most intensified and the most developed and profitable animal production enterprises in the world (Obiora, 1992). The fewer social and religious taboos related to the production, marketing and consumption of poultry products in relation to other livestock species makes it a preferred protein source worldwide (Beyene et al., 2014). In Nigeria, the poultry population is estimated to be 160 million; with chickens comprising about 72.4 million (Odenu et al., 2016). The industry contributes about $15 \%$ to the country's gross domestic product (GDP) and accounts for up to $36 \%$ of total protein intake of the country (Akintunde et al., 2015).

In Nigeria, the poultry industry is influenced by several diseases (Nnadi and George, 2010). Parasitism has been identified as one of the major factors that threaten poultry production in the country and most parts of the world (Adene and Dipeolu, 1975). Some of them are ectoparasites which hamper the maximum production of the sector. Ectoparasites are parasites which are found on the body/ sebaceous glands of animals and man. Ectoparasites can be found practically in all avian species. Several species of ectoparasites such as lice, fleas, ticks, mites and to some extent flies are known to infest poultry (Saidu et al., 1994; Mirzaei et al., 2016). They feed on blood, feathers, skin, and scales of their host. They may cause a range of symptoms, including discomfort, pain, irritation, loss of plumage, stunted growth, reduced egg production and hatchability, 
144

anemia, increased feed costs, elevated mortality, and susceptibility to other infections (Urquhart et al., 1996; Mirzaei et al., 2016). Ectoparasites are vectors / intermediate host for different helminthic parasites (Arends, 2003) and some poultry diseases, such as fowl pox, pasteurellosis, Newcastle disease, and in some cases Chlamydia (Nnadi and George, 2010). A proper control of poultry ectoparasitism during outbreaks includes the use of good management (hygienic) practices and through biological and/or chemical control methods such as dusting, spraying and fumigating of the poultry and poultry houses using selected acaricides, larvicides and fumigants (Nnadi and George, 2010; Mirzaei et al., 2016).

Studies on ectoparasites, one of the major causes of decrease in productivity of domestic avian species is rarely carried out (Dinka et al., 2010). Therefore, this study appears to be the foremost work on assessing the prevalence and associated risk factors of avian ectoparasitic infestations in Osun State, Nigeria. It is aimed to provide a base line epidemiological data on avian ectoparasitism in the State so as to assist in the formulation of policies by government for improved poultry production.

\section{Materials and Methods}

\section{Study area}

This study was conducted in Osun State Veterinary Hospitals, southwest Nigeria. The State covers an area of 9,026 square kilometers and is located between latitude $7^{\circ}$ $30^{\prime} \mathrm{N}$ and longitude $4^{\circ} 30^{\prime} \mathrm{E}$. The State is characterized by a tropical wet (March-October) and dry (NovemberFebruary and August) climate with a lowland tropical rain forest vegetation (Ola-Fadunsin, 2017). The state records a mean annual rainfall of between $127.8 \mathrm{~cm}$ and $159.8 \mathrm{~cm}$ and an average annual temperature ranging from $21.1^{\circ} \mathrm{C}$ to $31.9^{\circ} \mathrm{C}$. It records a mean relative humidity of between $58.7 \%$ and $79.7 \%$ (National Bureau of Statistics, 2016).

A ten-year Hospital records (January 2006 - December 2015) of avian species that were brought to the Hospitals for various reasons were collated from the major State Veterinary Hospitals located in Osogbo, Ilesa, Ede and Ikirun. From these records, data of diagnosed ectoparasitic infestations were extracted. The records included information such as bird type, age and sex as well as the date of presentation to the Hospital. According to the available data, the authors understood that the confirmation of avian ectoparasitism was carried out in the hospitals based on physical examination and stereomicroscopic examination of collected ectoparasites. The parasites were identified using the morphological characteristics as described by Soulsby (1982).

\section{Statistical analysis}

Statistical evaluation was carried out using the Chisquare $\left(\chi^{2}\right)$ test. Odds ratios with its $95 \%$ confidence interval were used to determine the association between each epidemiological factor and ectoparasitism. The odds ratios were calculated with respect to a reference category as indicated in the respective tables. All statistical tests were conducted using statistical package for social sciences
(SPSS) version 22 (SPSS Inc., Chicago). Significant level was set at $P<0.05$.

\section{Results}

Out of a total of 4,584 avian species presented to the hospitals during the study period, 324 (7.07\%) were infested with one or more ectoparasites. Lice infestation (216, 4.71\%; 95\% CI: 4.13-5.35) was the most prevalent ectoparasitic infestation, followed by flea infestation (72, 1.57\%; 95\% CI: 1.24-1.96). Mite infestation (12, 0.26\%; 95\% CI: 0.14-0.45) was the least prevalent (Table 1).

The undefined pattern in the yearly and monthly prevalence of avian ectoparasitic infestations is presented in Figs. 1 and 2. Lice infestation was most prevalent in 2009 recording 26.30\% while no case recorded in 2008 and 2010. Flea infestation was observed in 2012 (3.60\%) and 2013 (5.10\%). Mite infestation was only recorded in 2006 $(4.30 \%)$. There was a bimodal peak of tick infestation in 2009 (2.60\%) and 2015 (3.60\%). In the monthly prevalence, most of the lice infestation cases occurred in July (39.30\%) with none reported in January, June, September to December. Flea infestation was reported only in September and December with $9.10 \%$ and $12.50 \%$ prevalence, respectively. Mite infestation was observed only in October with $2.70 \%$ prevalence. Tick infestation was recorded in March and April only with a prevalence of $2.90 \%$ and $16.70 \%$ respectively.

Prevalence of the ectoparasitic infestation was higher in young birds $(229,8.59 \%)$ than adults $(95,4.95 \%)$, male $(182,9.13 \%)$ than female $(142,5.48 \%)$ and during the wet season $(286,9.97 \%)$ than the dry season $(38,2.21 \%)$. The highest infection rate $(198,9.48 \%)$ was observed in turkeys compared to $(72,7.06 \%)$ and $(54,3.66 \%)$ observed in the local chickens and layers, respectively. Statistically, all the hypothesized risk factors were significantly associated with the prevalence of ectoparasitic infestation $(P<0.05)$. Young, male and wet season categories were $1.80(95 \% \mathrm{CI}=1.41$ 2.32), $1.73(95 \% \mathrm{CI}=1.38-2.18)$ and $4.89(95 \% \mathrm{CI}=3.50-$ 6.98) times more likely to be infested by ectoparasites than adult, female and dry season categories, respectively. Turkeys were 1.38 (95\% CI=1.05-1.84) more likely, while layers were twice $(95 \% \mathrm{CI}=0.35-0.72)$ less likely to be infested by ectoparasites compared to local chickens (Table 2).

Lice and flea infestations were more prevalent in young, male and during the wet season than adult, female and dry season, respectively. Higher prevalence of mite infestation was observed among young, female and wet season compared to adult, male and dry season, respectively. Tick infestation was more prevalent in adult, male and wet season compared to young, female and dry season. Turkeys had the highest prevalence rate of lice, mite and tick infestations compared to the other bird types, while local chickens had the highest prevalence rate of flea infestation compared to turkeys and layers. The prevalence, risk estimate and the $95 \%$ confidence intervals for variables, presence or absence of statistical significant difference $(P=0.05)$ in the prevalence of each ectoparasitic condition are presented in Table 3. 
Table 1. Prevalence (\%) of ectoparasitic infestations among 4,584 avian species presented in the major Veterinary Hospitals in Osun State from $2006-$ 2015

\begin{tabular}{ccccc}
\hline Ectoparasites & Number positive & Percentage $(\%)$ & 95\% CI & $4.13-5.35$ \\
Lice & 216 & $4.71^{\mathrm{a}}$ & $1.57^{\mathrm{b}}$ & $0.24-1.96$ \\
Fleas & 72 & $0.26^{\mathrm{c}}$ & $0.14-0.45$ \\
Mites & 12 & $0.52^{\mathrm{c}}$ & $0.34-0.77$ \\
Ticks & 24 & $\mathbf{7 . 0 7}$ & $\mathbf{6 . 3 5 - 7 . 8 4}$ \\
Total & $\mathbf{3 2 4}$ & & \\
\hline
\end{tabular}

Different alphabets superscripts $(\mathrm{a}, \mathrm{b}, \mathrm{c})$ indicate significant differences $\left(\chi^{2}\right.$ test, $\left.P<0.05\right)$ between prevalence of ectoparasitic infestations.

Table 2. Prevalence of avian ectoparasitism and its association with hypothesized risk factors among 4,584 avian species presented in the major Veterinary Hospitals in Osun State from 2006-2015

\begin{tabular}{|c|c|c|c|c|c|}
\hline Risk factors & $\begin{array}{c}\text { Positive } \\
\text { (Prevalence in \%) }\end{array}$ & Negative (Prevalence in \%) & OR & $95 \% \mathrm{Cl}$ & $P$ value \\
\hline \multicolumn{6}{|l|}{ Age } \\
\hline Young & $229(8.59)$ & $2436(91.41)$ & 1.80 & $1.41-2.32$ & $<0.01^{*}$ \\
\hline Adult $^{a}$ & $95(4.95)$ & $1824(95.04)$ & 1.00 & & \\
\hline \multicolumn{6}{|l|}{ Sex } \\
\hline Male & $182(9.13)$ & $1812(90.87)$ & 1.73 & $1.38-2.18$ & $<0.01^{*}$ \\
\hline Female $^{a}$ & $142(5.48)$ & $2448(94.52)$ & 1.00 & & \\
\hline \multicolumn{6}{|l|}{ Season } \\
\hline Wet & $286(9.97)$ & $2582(90.03)$ & 4.89 & $3.50-6.98$ & $<0.01^{*}$ \\
\hline Dry $^{a}$ & $38(2.21)$ & $1678(97.79)$ & 1.00 & & \\
\hline \multicolumn{6}{|l|}{ Bird types } \\
\hline Turkeys & $198(9.48)$ & $1890(90.52)$ & 1.38 & $1.05-1.84$ & $0.02^{*}$ \\
\hline Layers & $54(3.66)$ & $1422(96.34)$ & 0.50 & $0.35-0.72$ & $<0.01^{*}$ \\
\hline Local chickens $^{\mathrm{a}}$ & $72(7.06)$ & $948(92.94)$ & 1.00 & & \\
\hline
\end{tabular}

Table 3. Prevalence and association between hypothesized risk factors with ectoparasitic infestations diagnosed among 4,584 avian species presented at the major Veterinary Hospitals in Osun State from 2006-2015

\begin{tabular}{|c|c|c|c|c|c|c|}
\hline \multirow{2}{*}{ Risk factors } & \multirow{2}{*}{ Category } & \multirow{2}{*}{ No. Presented } & \multicolumn{4}{|c|}{ No. Positive (prevalence in \%) } \\
\hline & & & Lice infestation & Flea infestation & Mite infestation & Tick infestation \\
\hline \multirow[t]{5}{*}{ Age } & Young & 2665 & $156(5.85)$ & $60(2.25)$ & $11(0.41)$ & $2(0.08)$ \\
\hline & Adult $^{\mathrm{a}}$ & 1919 & $60(3.13)$ & $12(0.63)$ & $1(0.05)$ & $22(1.15)$ \\
\hline & OR & & 1.93 & 3.66 & 7.95 & 0.07 \\
\hline & $95 \% \mathrm{Cl}$ & & $1.43-2.63$ & $2.01-7.11$ & $1.36-17.28$ & $0.01-0.24$ \\
\hline & $P$ value & & $<0.01^{*}$ & $<0.01^{*}$ & $0.02^{*}$ & $<0.01^{*}$ \\
\hline \multirow[t]{5}{*}{ Sex } & Male & 1994 & $132(6.62)$ & $36(1.81)$ & $2(0.10)$ & $12(0.60)$ \\
\hline & Female $^{a}$ & 2590 & $84(3.24)$ & $36(1.39)$ & $10(0.39)$ & $12(0.46)$ \\
\hline & OR & & 2.115 & 1.30 & 0.26 & 1.30 \\
\hline & $95 \% \mathrm{Cl}$ & & $1.60-2.81$ & $0.82-2.09$ & $0.04-1.06$ & $0.57-2.96$ \\
\hline & $P$ value & & $<0.01^{*}$ & 0.27 & 0.06 & 0.53 \\
\hline \multirow[t]{5}{*}{ Season } & Wet & 2868 & $192(6.70)$ & $60(2.09)$ & $11(0.38)$ & $23(0.80)$ \\
\hline & Dry $^{a}$ & 1716 & $24(1.40)$ & $12(0.70)$ & $1(0.06)$ & $1(0.06)$ \\
\hline & OR & & 5.057 & 3.03 & 6.60 & 13.86 \\
\hline & $95 \% \mathrm{Cl}$ & & $3.34-7.92$ & $1.67-5.89$ & $1.13-14.35$ & $2.59-28.88$ \\
\hline & $P$ value & & $<0.01^{*}$ & $<0.01^{*}$ & $0.03^{*}$ & $<0.01^{*}$ \\
\hline \multirow[t]{9}{*}{ Bird types } & Turkeys (T) & 2088 & $156(7.47)$ & $12(0.57)$ & $10(0.48)$ & $20(0.96)$ \\
\hline & Layers (L) & 1476 & $48(3.25)$ & $2(0.14)$ & $1(0.07)$ & $3(0.20)$ \\
\hline & Local chickens $^{a}$ & 1020 & $12(1.18)$ & $58(5.69)$ & $1(0.10)$ & $1(0.10)$ \\
\hline & $\mathrm{OR}(\mathrm{T})$ & & 6.78 & 0.10 & 4.90 & 9.85 \\
\hline & $95 \% \mathrm{Cl}(\mathrm{T})$ & & $3.87-12.81$ & $0.05-0.18$ & $1.82-10.75$ & $1.81-20.66$ \\
\hline & $P$ value (T) & & $<0.01^{*}$ & $<0.01^{*}$ & 0.09 & $<0.01^{*}$ \\
\hline & $\mathrm{OR}(\mathrm{L})$ & & 2.82 & 0.02 & 0.69 & 2.08 \\
\hline & $95 \% \mathrm{Cl}(\mathrm{L})$ & & $1.52-5.56$ & $0.004-0.078$ & $0.02-2.70$ & $0.22-5.7$ \\
\hline & $P$ value (L) & & $<0.01^{*}$ & $<0.01^{*}$ & 0.82 & 0.58 \\
\hline
\end{tabular}

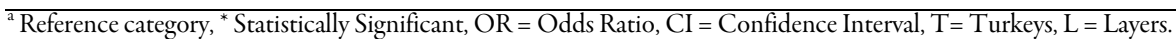


146

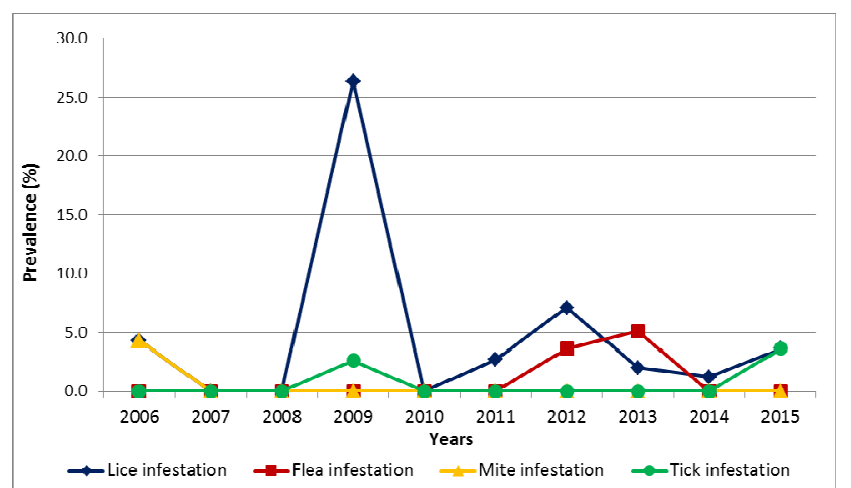

Fig. 1. Yearly prevalence (\%) of avian ectoparasitic infestations in the major Veterinary Hospitals in Osun State from 20062015.

\section{Discussion}

Ectoparasitism causes a major setback to the livestock industry especially the poultry sector. This study shows that ectoparasitism is one of the major conditions diagnosed in avian species in the study area. The low overall prevalence of $7.07 \%$ reported in this study is much lower than the $40.50 \%$ prevalence reported by Ikpeze et al. (2008) in their study conducted in Awka, southeast Nigeria and the 52.80\% prevalence reported by Mirzaei et al. (2016) in their study conducted in Iran. The disparity in these prevalences could be attributed to climate change, the regular use of acaricides and the management system adopted by poultry farmers in the study area. The intensive and semi-intensive management systems are the major methods of raising birds by farmers in the study area. Studies in Nigeria by Malann $e t$ al. (2016) and in Ethiopia by Firaol et al. (2014) has shown that birds raised in the extensive management system are significantly more prone to ectoparasite infestations compared to birds raised intensively and semi-intensively. The high prevalence of ectoparasites infestation associated with extensive management system may be due to the following: (a) the unrestricted ranging system which exposes the birds to various ectoparasites, and (b) the poor housing facilities which creates hiding places for the ectoparasites. The above makes it difficult to institute adequate treatment and control measures against the parasites.

Lice infestation was the most prevalent ectoparasitic conditions in this study. Lice have been reported to be the most abundant and widely spread ectoparasites affecting chickens in most parts of the world (Ikpeze et al., 2008). Studies in Nigeria (Nnadi and George, 2010; Malann et al., 2016), Ethiopia (Firaol et al., 2014), Kenya (Sabuni et al., 2010), Iran (Mirzaei et al., 2016) and Thailand (Tanasak et al., 2009) have reported that lice infestation is the most prevalent ectoparasite affecting chickens. The fact that lice are highly adapted and abundant in hot and humid areas such as Nigeria (Fabiyi, 1988) could be the reason for it having the highest prevalence compared to the other ectoparasites.

The undefined yearly and monthly prevalence pattern of ectoparasitism could be attributed to the inability of poultry farmers to consistently and properly maintain a standard hygienic practice in their farms. It may also be due to the off and on participation of farmers in the poultry business in Osun State.

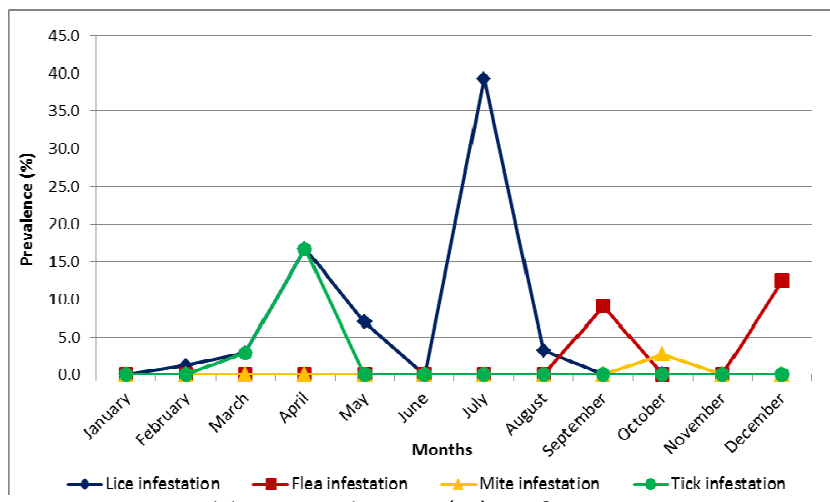

Fig. 2. Monthly prevalence (\%) of avian ectoparasitic infestations in the major Veterinary Hospitals in Osun State from 2006-2015

Generally, higher prevalence of ectoparasitic infestations was recorded in young birds compared to adults and it was statistically significant. Similarly, higher prevalence of ectoparasites has been reported in young birds compared to adult birds by Mirzaei et al. (2016) and Oche et al. (2016). This may be is due to the soft skin and feathers possessed by young birds making it easier for the ectoparasites to pierce and feed as they are known to feed on blood, feathers, skin and scales of their host. Also, the higher susceptibility recorded in young birds may be due to the limited strength applied in grooming themselves which is a way of reducing the intensity of ectoparasites on the body. Also, the poor immunity of the young chicken may have resulted in the higher prevalence recorded in this age category. The significantly higher prevalence of avian ectoparasitic infestations observed in male than female may be attributed to the fact that male chickens mate with several females, thereby increasing the chances for the male to be infested. Tolossa and Tafesse (2013) and Firaol et al. (2014) reported higher prevalence of ectoparasitic infestations in male birds compared to female. Season was significantly associated with the prevalence of ectoparasitic infestations in this study. Higher prevalence was observed during the wet season compared to the dry season. Odenu et al. (2016) documented arthropods (lice, ticks, fleas, and mites) to be abundant during the wet season. The optimal temperature and the maximum moisture present during rainy season favors the breeding of arthropod vectors and this might be the reason for the higher prevalence recorded during the wet season. Significantly higher prevalence of ectoparasitic infestations was recorded in turkeys and indigenous birds compared to layers. This may be associated with the scavenging behavior of these two bird types due to a lesser management care that is given to them compared to layers that are basically raised for egg production. Higher infestation rate of ectoparasites has been reported in local birds compared to exotic (layers, cockerels) birds (Firaol et al., 2014; Malann et al., 2016).

Individually, most of the ectoparasitic conditions followed the observed general prevalence pattern with few exceptions, such as: (a) adult birds having a significantly higher prevalence of tick infestation compared to young birds. (b) higher prevalence rate of mite infestation observed in female than male, although the difference was not significant and (c) layers having higher prevalence rate of 
lice and tick infestations compared to local chickens with the difference of the latter not significant. Malann et al. (2016) reported a higher prevalence rate of ectoparasites among adult birds compared to young birds.

\section{Conclusions}

The result of this study evidently shows that $7.07 \%$ of the birds are infested with one or more ectoparasites, with lice and flea infestations been the most prevalent. Age, sex, season and species were the important risk factors statistical associated with the prevalence of ectoparasitism in the area. Therefore, there is a need for increased input in terms of prevention and control measures so as to reduce ectoparasites to economically accepted level and enhance productivity in the poultry sector of the State.

\section{References}

Adene DF, Dipeolu OO (1975). Survey of blood and ectoparasites of domestic fowls in Ibadan, Western State of Nigeria. Bulletin Animal Health and Production in Africa 23:333-335.

Akintunde OK, Adeoti AI, Okoruwa VO, Omonona BT, Abu AO (2015). Effect of disease management on profitability of chicken egg production in Southwest Nigeria. Asian Journal of Poultry Science 9:118.

ArendsJJ (2003).External Parasites and Poultry Pests. In: Calnek WB, John H, Beard WC, Mc Dougald L.R, Saif YM (Eds). Diseases of Poultry. IowaStatePress (11thEd), Ames, Iowapp 905-930.

Beyene K, Bogale B, Chanie M (2014). Study on effects and occurrence of nematodes in local and exotic chickens in and around Bahir Dar, Northwest Ethiopia. American-Eurasian Journal of Science Research 9:62-66.

Changbunjong T, Buddhirongawatr R, Suwanpakdee S, Siengsanan J, Yongyuttawichai P, Cheewajorn K, Jangiaras J, Sangloung C, Ratanakorn P (2009). A survey of ectoparasitic arthropods on domestic animals in Tak Province, Thailand. Southeast Asian Journal of Tropical Medicine and Public Health 40(3):435-442.

Dinka H,Chala R, Dawo F, Bekana E, Leta S (2010). Major constraints and health management of village poultry production in Rift Valley of Oromia, Ethiopia. American-Eurasian Journal of Agricultural and Environmental Science 9:529-533.

Fabiyi JP (1988). Lice infestation of domestic chicken in Nigeria. Bulletin of Animal Health Production in Africa 36:390-394.

Firaol T, Dagmawit A, Askale G, Solomon S, Morka D, Waktole T (2014). Prevalence of ectoparasite infestation in chicken in and around Ambo Town, Ethiopia. Journal of Veterinary Science and Technology 5:189193.

Ikpeze OO, Amagba IC, Eneanya CI (2008). Preliminary survey of ectoparasites of chicken in Awka, South-eastern Nigeria. Animal Research International 5:848-851.
Malann YD, Olatunji BO, Usman AM (2016). Ectoparasitic infestation on poultry birds raised in Gwagwalada area council, FCT-Abuja. International Journal of Innovative Research and Development 5:74 77.

Mirzaei M, Ghashghaei O, Yakhchali M (2016). Prevalence of ectoparasites of indigenous chicken from Dalahu Region, Kermanshah Province, Iran. Turkiye Parazitoloji Dergisi 40:13-16.

Mohammed BR, Sunday OS (2015). An overview of the prevalence of avian coccidiosis in poultry production and its economic importance in Nigeria. Veterinary Research International 3:35 45.

National Bureau of Statistics (2016). Annual abstract of statistics. Federal Republic of Nigeria Retrieved 2017 December 18 from http://www.nigerianstat.gov.ng/pdfuploads/annual_abstract_2012.pd f.

Nnadi P, GeorgeS (2010). A cross-sectional survey on parasites of chickens in selected villages in the sub-humid zones of South-Eastern Nigeria. Journal of Parasitology Research http://dx.doi.org/10.1155 /2010/141824.

Obiora FC (1992). A guide to poultry production in the tropics. Acena Publishers (1sted),Enugu, Nigeria.

OcheDA, Ogwiji O, Torhemen M, Andyar AC, AkahaanRT,LugaZT, .... Kwaghtse WR (2016). Survey of ecto-parasites in chickens in Benue State of Nigeria Scholarly Journal of Agricultural Science 6:235-238.

Odenu RA, Mohammed BR, Simon MK, Agbede RIS (2016). Ectoparasites of domestic chickens (Gallus gallusdomesticus) in Gwagwalada Area Council, Abuja, Nigeria-West Africa. Alexandria Journal of Veterinary Sciences 51:140-146.

Ola-Fadunsin SD (2017). Retrospective occurrence and risk factors associated with cattle parasitic infections in Osun State, Nigeria. Nigerian VeterinaryJournal 38(3):195-209.

Sabuni ZA, Mbuthia PG, Maingi N, Nyaga PN, Njagi LW, Bebora LC, Michieka JN (2010). Prevalence of ectoparasites infestation in indigenous free-rangingvillage chickens in different agro-ecological zones in Kenya. Livestock Research for Rural Development 22(11) http://www.lrrd.org/lrrd22/11/sabu22212.htm.

Saidu L, Abdu PA, Umoh JU, Abdullahi US (1994). Diseases of Nigerian indigenous chicken. Bulletin of Animal Health Production in Africa 23:333-335.

Soulsby EJL (1982). Helminths, arthropods and protozoan's of domesticated animals. Bailliere Tindall (7thed), London.

Tolossa YH, Tafesse HA (2013). Occurrence of ectoparasites and gastrointestinal helminthes infections in Fayoumi chickens (Gallus gallus Fayoumi) in Debre Zeit Agricultural Research Center Poultry Farm, Oromia region, Ethiopia. Journal of Veterinary Medicine and Animal Health 5:107-112.

Urquhart GM, Armour J, Duncan JL, Dunn AM, Jennings FW (1996). Veterinary parasitology. Churchill Livingstone Inc, New York. 